\title{
Sobre el mensajero trágico: propuesta de clasificación"
}

\author{
RAQUEl FoRNIELES SÁNCHEZ \\ Universidad Autónoma de Madrid \\ raquel.fornieles@uam.es
}

\section{Introducción}

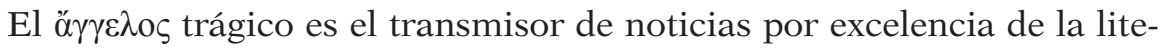
ratura griega y cumple una función muy concreta: introducir información "extraescénica" ligada estrechamente a la acción y que, por distintas razo$n^{1}{ }^{1}$, no podría representarse ante los espectadores. Aunque la escena de mensajero es una convención consolidada, los autores que la han estudiado no coinciden en el establecimiento de un catálogo general y se debate qué

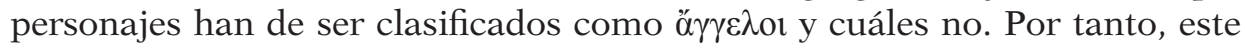
trabajo pretende contribuir a avanzar en las reflexiones de los estudiosos y ofrece, además, una propuesta propia de clasificación en la que destaca la inclusión de un criterio novedoso: la consideración del léxico que permita identificar al personaje en cuestión como ő $\gamma \gamma \varepsilon \lambda o s$.

\section{Propuesta de definición del mensajero trágico}

El estudio del léxico permite realizar una primera aproximación a la

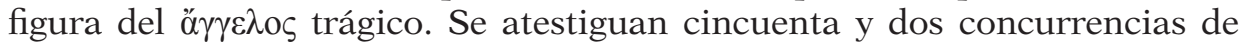

* Recebido em 11-12-2017; aceite para publicação em 14-06-2108.

** Este trabajo es una pequeña parte de una tesis doctoral en la que se estudia el concepto de noticia a partir del examen de la familia léxica derivada de ö $\gamma \gamma \varepsilon \lambda o \varsigma$ en un extenso corpus. El capítulo VI de dicha tesis está dedicado al análisis de las tragedias que conservamos completas de Esquilo, Sófocles y Eurípides. Agradezco a Luz Conti todos sus comentarios y observaciones.

1 Al respecto, J. M. Bremer, "Why Messenger-Speeches", in J. M. Bremer, S. Radt, C. J. Ruijgh (edd.), Miscellanea tragica in honorem J. C. Kamerbeek, Amsterdam, apud A. Hakkert, 1976, pp. 29-48, que identifica cinco motivos que justifican las escenas de mensajero: mantener la unidad de lugar, relatar escenas de muchedumbre, transmitir milagros y sucesos sobrenaturales, narrar las muertes y mantener la tradición literaria con un relato narrativo entroncado con la oralidad de la literatura arcaica. 


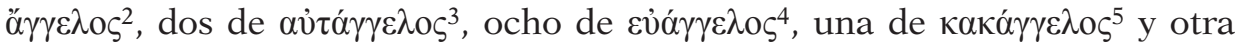

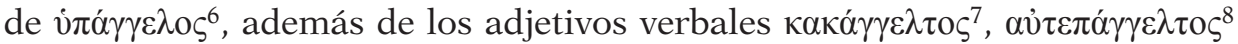
y vé́ $\gamma \gamma \varepsilon \lambda \tau o \varsigma^{9}$. Los mensajeros del drama poseen una voz inteligible y sensata (A. Ch. 195) y son veloces (A. A. 280) y presurosos (A. Th. 285). Si sus noticias son malas se aproximan con el rostro entristecido (A. A. 639) o sombrío (E. Ph. 1333). Cuando el heraldo de Agamenón entra en escena, afirma que no conviene manchar un día feliz con una lengua mensajera de malas noticias (A. A. 636) y algunos personajes evidencian que el ö $\gamma \gamma \varepsilon \lambda o \varsigma$ es mensajero de desgracias (S. Ant. 277). Con menos frecuencia sus noticias son buenas y,

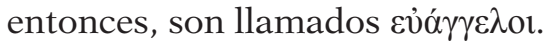

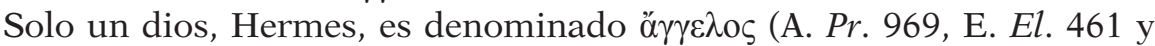

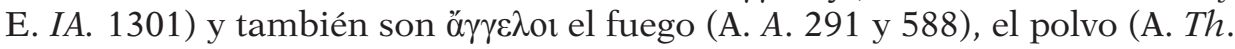
82 y A. Supp. 180), la lengua (E. Supp. 203), el grito (E. Heracl. 656) y un pájaro (S. El. 149).

Por otra parte, los manuscritos indican la presencia de numerosos

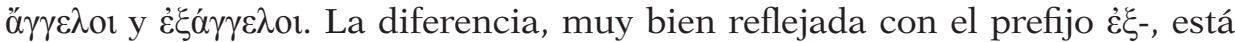
en que el ớ $\gamma \gamma \varepsilon \lambda o \varsigma$ llega a escena desde un lugar distante, mientras que el

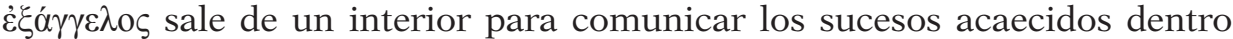
de palacio o tras la escena ${ }^{10}$. La mayoría son anónimos ${ }^{11}$. Por citar solo algunos casos, en Esquilo los manuscritos nos presentan a un mensajero espía

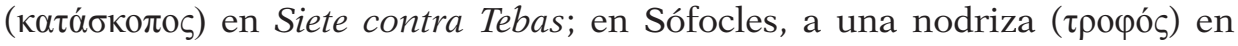
Traquinias, o a un pedagogo ( $\pi \alpha 1 \delta \alpha \gamma \omega \gamma o ́ \varsigma)$ en Electra y, en Eurípides, a una

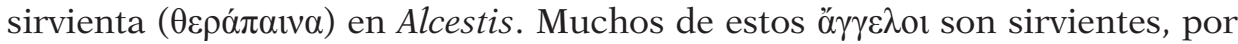
lo que se presupone su lealtad (A. Pr. 969) y su fiabilidad (A. Th. 82) ${ }^{12}$.

\section{Estado de la cuestión}

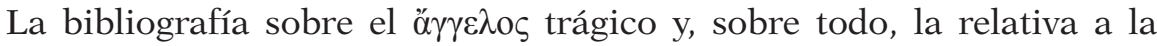
escena de mensajero es muy abundante ${ }^{13}$. La cuestión de la catalogación de

2 Diecisiete en Esquilo, doce en Sófocles y veintitrés en Eurípides. Nuestro estudio está centrado en las piezas que conservamos completas de los tres tragediógrafos.

3 Cf. S. OC. 333 y S. Ph. 568.

4 "Mensajero de buenas noticias". Cf. A. A. 21, 262, 264, 475 y 646, E. Ph. 1217, E. Med. 975 y E. Med. 1010.

5 "Mensajero de malas noticias". Cf. A. A. 636.

6 "Convocado por un mensajero". Cf. A. Ch. 838.

7 Referido al dolor causado por las malas noticias. Cf. S. Ant. 1286.

8 "Ofrecerse voluntario". Cf. E. HF. 706.

9 Cf. A. Ch. 736.

10 Cf. L. Di Gregorio, Le scene d'annunzio nella tragedia greca, Milán, Vita e Pensiero, 1967, pp. 3 y 54, que nos remite a un pasaje de Filóstrato (Philostr. VS 1.9).

11 Sobre algunos de estos personajes, F. Yoon, The Use of Anonymous Characters in Greek Tragedy. The Shaping of Heroes, Amsterdam, Brill, 2017.

12 O. Longo, "Tecniche della comunicazione e ideologie social nella Grecia antica", Quaderni Urbinati Di Cultura Classica, 27, 1978, 63-92 afirma que una noticia fielmente transmitida solo puede ser interpretada como cierta.

13 E inabarcable para un trabajo de estas características. Además de todos los que iremos mencionando, destacamos los siguientes estudios: D. BASSI, "Il nunzio nella tragedia greca", 
los personajes que han de ser considerados ö $\gamma \gamma \varepsilon \lambda \mathrm{ol}$ - entendiendo como tales aquellas figuras que intervienen para transmitir noticias y que protagonizan una escena de mensajero - ha generado mucho debate y ha sido objeto de reconsideraciones metodológicas en los últimos años, como muestran, sobre todo, las últimas aportaciones de Brioso Sánchez y Campos Daroca.

En su estudio sobre la evolución del mensajero y su relato, Di Gregorio ${ }^{14}$ no tiene en cuenta la identidad del personaje, sino el contenido narrativo de su intervención. Prueba de ello es que ejemplifica con las Suplicantes de

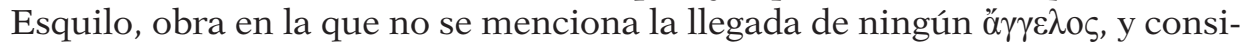
dera que Dánao ha de ser considerado como tal.

Bremer ${ }^{15}$ menciona dos tipos intervenciones de los mensajeros. Por un lado, las escenas que incluyen los que él denomina relatos de mensajero en sentido estricto, es decir, los pronunciados por personajes que no están envueltos en la acción dramática y cuya única función es informar y, tras hacerlo, marcharse. Por otro, algunos que están muy cercanos a los verdaderos relatos de mensajero y que son emitidos por personajes implicados en la trama, como el ya citado caso de Dánao en Suplicantes de Esquilo, el de Hilo en Traquinias o el de Ismene en Edipo en Colono.

Rijksbaron ${ }^{16}$ defiende que hay al menos un relato de mensajero en todas las obras euripideas excepto en Troyanas y que, aunque este personaje habi-

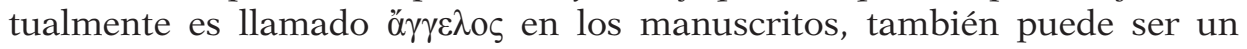

Rivista Di Filologia e d' Istruzione Classica, 27, 1899, 50-89; E. HeNnING, De tragiccorum atticorum narrationibus (Tesis doctoral), Göttingen, 1910; J. CAVERno, "The Messenger in Greek Tragedy", The Classical Journal, 12, 1917, 263-270; J. KELLER, Struktur und dramatische Funktion des Botenberichtes bei Aischylos und Sophokles (Tesis doctoral), Tübingen Universität, 1959; G. ERdmann, Der Botenbericht bei Euripides: Struktur und dramatsiche Funktion (Tesis doctoral), Kiel, 1964; L. Di Gregorio, op. cit.; J. M. Bremer, loc. cit.; S. Goldhill, Reading Greek Tragedy, Cambridge, University Press, 1986; M. QuiJada SAgredo, La composición de la tragedia tardia de Eurípides, Vitoria, Universidad del País Vasco, 1991; G. Monaco, "La scena allargata in Eschilo, Sofocle, Plauto", Dioniso, 3, 2004, 7-34; S. R. PERris, "What maketh the Messenger? Reportage in Greek Tragedy", in A. Mackay (ed.), Australasian Society for Classical Studies 32 Proceedings, $2011^{a}$, pp. 1-12; M. C. ENCINAS REguero, "El relato de mensajero en el Orestes de Eurípides", Emerita, 79, 2011, 131-154 y M. C. ENCINAS REguero, "Los relatos de mensajero y la problematización de la visión en Bacantes de Eurípides", Exemplaria, 18, 2014, 5-21; M. BRIOSO SÁNCHEZ, "Algunas observaciones sobre el mensajero en el teatro ático clásico", in M. Calderón, A. Morales, M. Valverde (edd.), Koinós Lógos. Homenaje al profesor José García López, Murcia, Universidad de Murcia, 2006, pp. 111-119; M. BRIoso SÁnchez, "De nuevo sobre los mensajeros trágicos: un debate metodológico”, in M. Quijada Sagredo, M. C. Encinas Reguero (edd.), Retórica y discurso en el teatro griego, Madrid, Ediciones Clásicas, 2013, pp. 157-192.

14 Op. cit.

15 Op. cit., p. 33.

16 A. RiJKsbaron, "How does a Messenger begin his Speech?", in J. M. Bremer, S. Radt, C. J. Ruijgh (edd.), Miscellanea tragica in honorem J. C. Kamerbeek, Amsterdam, apud A. Hakkert, 1976, pp. 293-308. Rijksbaron excluye Cíclope y Reso argumentando que la primera es un drama satírico y la segunda no es de Eurípides. En cuanto a Troyanas, destaca que Taltibio desempeña

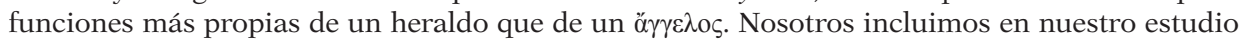
tanto Cíclope como Reso y, respecto a Troyanas, compartimos la opinión de Rijksbaron y exclui-

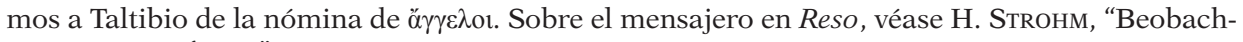
tungen zum Rhesus", Hermes, 87, 1959, 257-274. 
$\theta \varepsilon \rho \alpha ́ \pi \omega v$ o cualquier otra figura que refiera acontecimientos acaecidos fuera de escena.

Taplin ${ }^{17}$ establece tres elementos necesarios en toda escena de mensajero: un testigo visual de los hechos, un relato narrativo muy extenso (entre ochenta y cien versos) y una función dramática global. Por su parte, De Jong ${ }^{18}$ afirma que el mensajero no es un protagonista del drama, sino

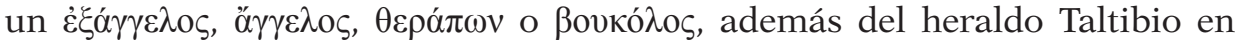
Hécuba ${ }^{19}$. De Jong fija otros dos criterios: que el relato incluya un número significativo de verbos en pasado y en presente histórico y la presencia del diálogo introductorio que el mensajero mantiene con el coro o con algún otro personaje justo antes de pronunciar su extenso relato.

Goward $^{20}$ cataloga como mensajeros a Tecmesa en Ayante y a Hilo en Traquinias y sostiene que tras sus relatos subyace una intención poética de Sófocles, que los introduce para facilitar que la acción avance y como mecanismo para incrementar el pathos dramático presentando a personajes importantes que sufren al relatar destinos trágicos.

Barrett ${ }^{21}$ parte de los criterios de De Jong $\mathrm{y}$, aunque considera que el anonimato es fundamental, incluye en su catálogo a Hilo en Traquinias. Sin embargo, descarta a Dánao en Suplicantes de Esquilo, a Tecmesa en Ayante y a Ismene en Edipo en Colono.

Dickin $^{22}$ tiene en cuenta el número de verbos de acción empleados en el relato de mensajero y utiliza el término reporting figure para referirse a cualquier personaje del drama cuya función principal es transmitir noticias. Dickin considera reporting figures tanto a los mensajeros convencionales como a otros personajes anónimos, incluyendo a los heraldos que comunican noticias y a quienes están implicados en el desarrollo de la acción y que

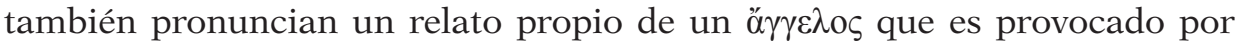
las noticias que van a transmitir. A estos últimos, los denomina aristocratic messengers.

Brioso Sánchez retomó el debate y se centró en Edipo en Colono, en concreto en Ismene, que anuncia las muertes de Eteocles y Polinices. Según Brioso $^{23}$ - y compartimos su opinión - al hecho de que estamos ante una

17 O. TAPLin, The Stagecraft of Aeschylus, Oxford, Clarendon Press, 1977, pp. 81-82.

18 I. De Jong, Narrative in Drama: the Art of the Euripidean Messenger-Speech, Leiden, Brill, 1991, pp. 179-180.

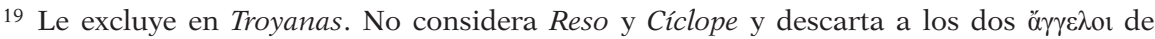
Ifigenia en Áulide.

20 B. Goward, Telling Tragedy, London, Duckworth, 1999, pp. 26 y ss.

21 J. BARRETT, Staged Narrative: Poetics and the Messenger in Greek Tragedy, Berkeley, University of California Press, 2002, pp. 223-224. Barrett incluye Reso y Cíclope, aunque no considera ă $\gamma \gamma \varepsilon \lambda \circ \varsigma$ a Ulises.

22 M. Dickin, A Vehicle for Performance: Acting the Messenger in Greek Tragedy, Lanham, University Press of America, 2009. Los aristocratic messengers son Dánao y Orestes en Suplicantes de Esquilo y Coéforos, Tecmesa, Hilo y Neoptólemo en Ayante, Traquinias y Filoctetes y

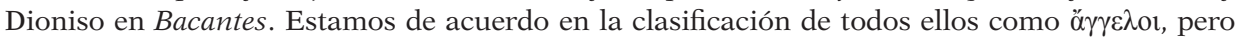
consideramos que también deben ser catalogados como tales Orestes en Coéforos, Ismene en Edipo en Colono y Ulises en Cíclope.

23 M. BRioso SÁNCHEZ, “Aspectos problemáticos del mensaje y el mensajero en la tragedia griega: el caso de Edipo en Colono”, in L. M. Campos, G. Santana (edd.), Homenaje al Profesor 
escena planteada exactamente como las habituales de mensajero, se añade

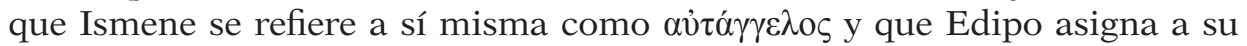
hija un papel informativo diferenciado (vv. 344-360).

Más recientemente, Campos Daroca ${ }^{24}$ ha propuesto un análisis funcional $^{25}$ del mensajero trágico con el propósito de clarificar su singularidad como figura de la comunicación dramática y realiza una catalogación de los mensajeros en los tres autores trágicos y en las tragedias fragmentarias ${ }^{26}$.

\section{Propuesta de clasificación}

En las siguientes páginas exponemos los criterios que consideramos que deben ser tenidos en cuenta para identificar a los ö $\gamma \gamma \varepsilon \lambda$ o y que nos permiten proponer un catálogo de personajes que, en nuestra opinión, han de clasificarse como ö $\gamma \gamma \varepsilon \lambda$ or en la tragedia.

\subsection{Que desempeñe una función claramente informativa}

Si tenemos en cuenta que el ő $\gamma \gamma \varepsilon \lambda o \varsigma$ es un personaje creado para comunicar noticias, el primer criterio que debe considerarse es evidente: ha de cumplir un rol notoriamente informativo, es decir, debe transmitir nuevas relevantes para quienes están en escena y para el público ${ }^{27}$. En la mayoría de

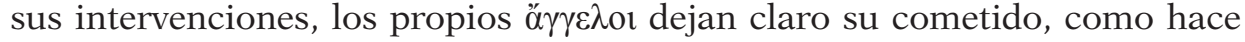
este ö $\gamma \gamma \varepsilon \lambda$ os en Ayante:

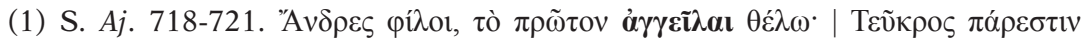

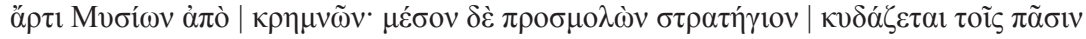

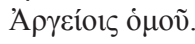

¡Amigos! En primer lugar, quiero anunciaros una noticia: Teucro acaba de presentarse procedente de los muros de Misia. Pero al llegar a la tienda del general es insultado por todos los griegos al mismo tiempo. ${ }^{28}$

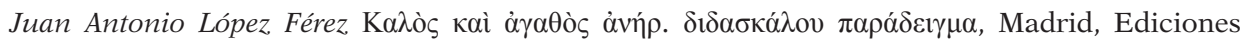
Clásicas, 2006, p. 124.

24 F. J. CAmpos Daroca, "Mensajeros y escenas de anuncio. Esbozo de análisis dramático de una singularidad trágica”, in F. De Martino, C. Morenilla (edd.), A la sombra de los héroes, Bari, Levante Editori, 2014, pp. 69-102. Destaca también en este trabajo el examen crítico de una extensa bibliografía.

25 F. J. CAMPOS DAROCA, op. cit., p. 81: "Nuestra propuesta funcional parte de la importancia central que el género trágico concede al problema de la adquisición del conocimiento en el curso del tiempo dramático".

26 En el mismo volumen, Romero Mariscal estudia la figura del mensajero en los fragmentos de Eurípides. Cf. L. P. Romero MARISCAL, "Mensajeros y escenas de mensajero en los fragmentos de Eurípides”, in F. De Martino, C. Morenilla (edd.), A la sombra de los héroes, Bari, Levante Editori, 2014, pp. 249-267.

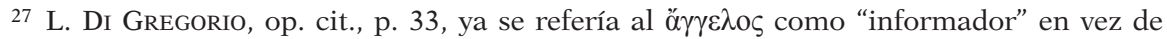
como mensajero. De igual modo opina W. S. BARRETT, Euripides: Hippolytus, Oxford, Clarendon Press, 2001, p. 377.

28 Todas las traducciones son propias. 


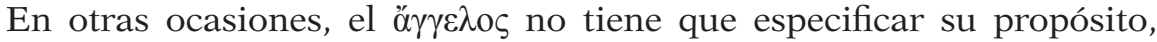
pues ya lo hacen por él los personajes ante los que se presenta. En (2), Dioniso anuncia la llegada de un mensajero que informará de la locura que se ha desatado entre las bacantes ${ }^{29}$ :

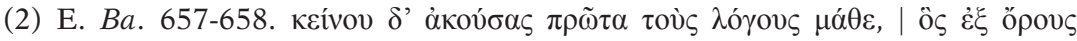

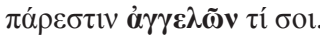

Pero, tras escuchar primero a aquel, que acude desde los montes para anunciarte algo, entérate de sus palabras.

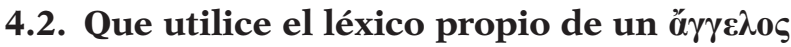

Los ejemplos (1) y (2) presentan un factor común: en ambos aparece $\dot{\alpha} \gamma \gamma \varepsilon \dot{\lambda} \lambda \lambda \omega$ y este hecho no es fortuito. El estudio de la familia léxica derivada

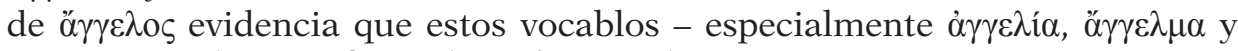
$\dot{\alpha} \gamma \gamma \varepsilon \dot{\varepsilon} \lambda \lambda \omega$ - se han configurado en la tragedia como términos técnicos especializados para la difusión de noticias asociados al mensajero. La prueba está en que en un alto porcentaje de contextos en los que se atestiguan $\alpha \gamma \gamma \varepsilon \lambda \lambda^{i} \alpha$ (en el setenta por ciento de los casos), $\alpha \gamma \gamma \gamma \varepsilon \lambda \mu \alpha$ (en el ochenta por ciento) y

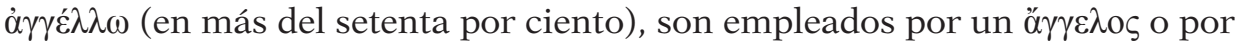

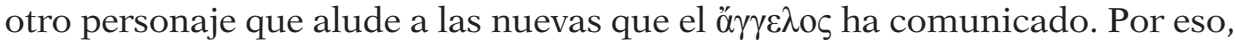
el segundo criterio que fijamos es el léxico. El rol informativo del mensajero debe quedar señalado en algún momento, bien porque él mismo u otro personaje se refiera a él como ơ $\gamma \gamma \varepsilon \lambda o s$, bien porque él - $\mathrm{u}$ otra persona que aluda a las noticias que este anuncia - use los términos derivados de ö $\gamma \gamma \varepsilon \lambda \circ \varsigma$ para llevar a cabo su cometido.

Por este motivo, en nuestra opinión, personajes como Dánao en Suplicantes de Esquilo - que además cumple el resto de criterios que proponemos - deben ser catalogados como ó $\gamma \gamma \varepsilon \lambda$ or. El rey entra en escena para desempeñar una función informativa. Transmite la noticia en cuanto llega: "La asamblea ha votado a nuestro favor" (A. Supp. 601) y, cuando el coro le pide detalles, alude a su función de este modo:

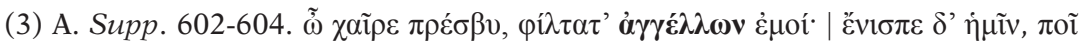

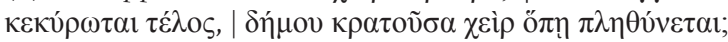

¡Salud, anciano, que anuncias las nuevas más queridas para mí! Cuéntame cómo fue el sufragio. ¿De qué manera la mano popular logró el triunfo?

Después, justo antes de abandonar la escena, el propio Dánao afirma

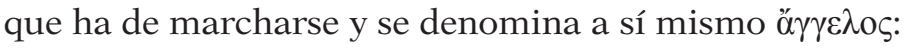

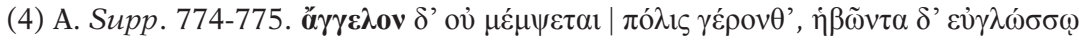

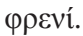

La ciudad no hará reproches a un mensajero anciano, pero que es joven por su lengua y su corazón.

29 Sobre esta escena, véase O. TAPLIN, Greek Tragedy in Action, London, Routledge, 1978; para el posterior relato, A. RIJKSBARON, Grammatical Observations on Euripides' Bacchae, Amsterdam, Gieben, 1991. 
En escasas ocasiones no encontramos testimonios del léxico deriva-

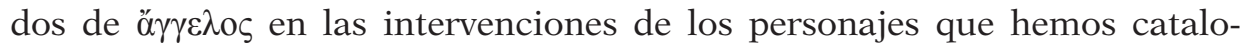
gado como tales, pero en estos casos utilizan otras expresiones que, como bien apunta Hutchinson ${ }^{30}$, son una fórmula estandarizada para introducir

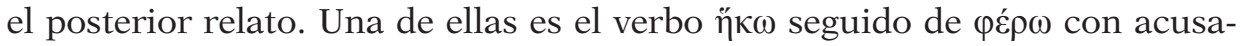

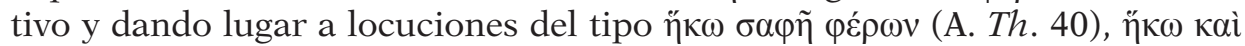

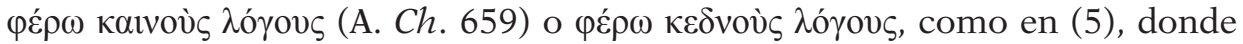

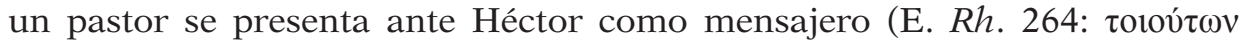

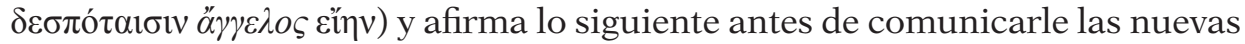
(la llegada de su aliado Reso):

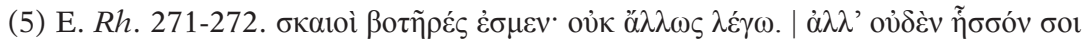

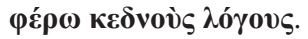

Groseros somos los pastores, no digo otra cosa. No obstante, te traigo buenas noticias.

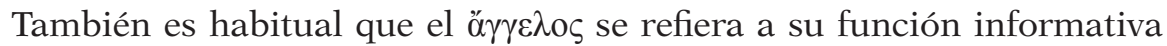

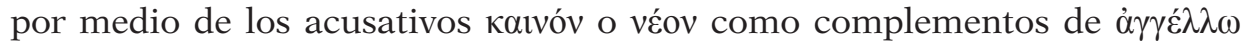
o de otros verbos de habla, como $\lambda \dot{\varepsilon} \gamma \omega, \varphi \eta \mu i ́, \varphi \rho \alpha ́ \zeta \omega ~ o ~ \sigma \eta \mu \alpha i ́ v \omega^{31}$, o con otros

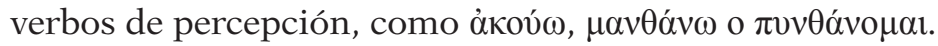

\subsection{Que protagonice una escena de mensajero con una estructura tripartita}

La escena de mensajero varía a medida que evoluciona el propio teatro griego $^{32}$. Aunque inicialmente debió tratarse de una simple $\dot{\rho} \tilde{\sigma} \sigma \varsigma$ narrativa que no se alteraba ${ }^{33}$, poco a poco se desarrollaron otros esquemas en los que la $\dot{\rho} \tilde{\sigma} \iota \varsigma$ iba seguida o precedida de un diálogo ( $\dot{\rho} \tilde{\eta} \sigma ı \varsigma$ + esticomitia o estico-

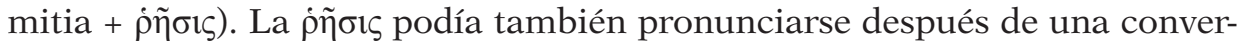
sación y estar seguida por otra (esticomitia + $\dot{\rho} \tilde{\sigma} \sigma \varsigma$ + esticomitia). La mayoría de escenas de mensajero presentan dicha estructura tripartita, a cuyas

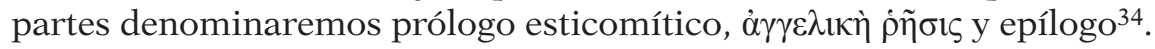

30 G. O. Hutchinson, Aeschylus: Septem contra Thebas, Oxford, Clarendon Press, 1985, p. 48.

31 Seguimos a D. J. Mastronarde, Euripides: Medea, Cambridge, University Press, 2002, p. 352 a partir de un pasaje de Medea (E. Med. 1120): "кavóv: news from a messenger-figure is

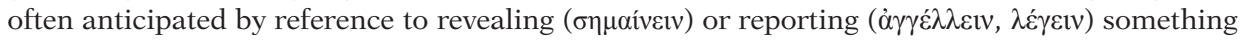
каıvóv or véov".

32 Sobre el origen de esta escena, J. M. LuCAS DE Dios, La estructura de la tragedia de Sófocles, Madrid, Instituto Antonio de Nebrija, 1982, pp. 259 y ss. Para la influencia de la épica,

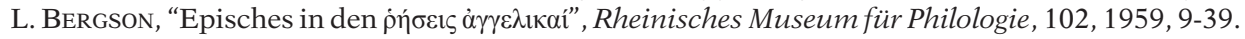

33 H. GuzMán García, "La escena del mensajero en la tragedia griega”, in A. Pérez Jiménez, G. Cruz Andreotti (edd.), Aladas Palabras. Correos y comunicaciones en el Mediterráneo, Madrid, Ediciones Clásicas, 1999, p. 154.

34 Partimos de la propuesta de J. M. MARcos Pérez, "El relato de mensajero en Eurípides: concepto y estructura”, Minerva, 9, 1994, 77-98, aunque preferimos referirnos a $\dot{\eta} \sigma 1 \varsigma$ en vez de a "cuerpo". A veces, tras el epílogo hay otra conversación, aunque lo habitual es que el mensajero abandone la escena. 


\section{a) El prólogo esticomítico}

La entrada del ó $\gamma \gamma \varepsilon \lambda o \varsigma$ en escena se produce de dos maneras. Su llegada es, con frecuencia, anunciada por el corifeo ${ }^{35}$ o por otro personaje ${ }^{36}$. Si nadie le presenta, suele preguntar por el destinatario de sus noticias ${ }^{37}$ o irrumpe dejando claro su propósito ${ }^{38}$ :

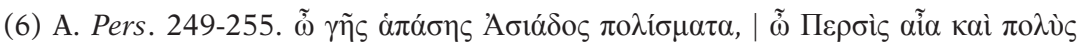

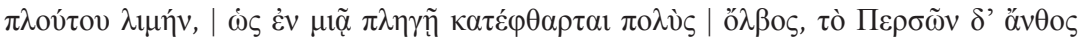

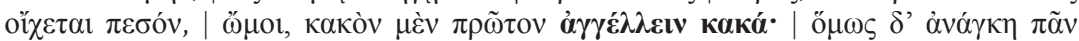

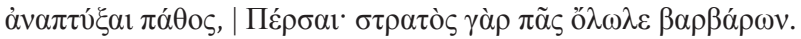

¡Oh, ciudades de toda la tierra de Asia! ¡Oh, país persa y puerto abundante en riqueza! ¡Cómo de un solo golpe ha sido destruida por completo la numerosa dicha! ¡La flor de los persas ha caído muerta! ¡Ay de mí! ¡Mi primera desgracia es anunciar desgracias! Y, sin embargo, es forzoso que os revele todo el desastre, persas. ¡Sí, el ejército bárbaro al completo ha perecido!

En cuanto comunica la noticia, el mensajero mantiene un breve diálogo con el receptor ${ }^{39}$ que sirve para intensificar el dramatismo y para que el interlocutor amplíe la información antes de conocer los detalles. La conversación se cierra con una $\Pi$-question ${ }^{40}$ con la que el destinatario de las nuevas invita al mensajero a iniciar su relato, con un imperativo ${ }^{41}$ o con ambos recursos ${ }^{42}$.

35 Cf. A. A. 490-492, A. Th. 369-771, S. Tr. 731-733 y 869-870, S. Ph. 539-541, E. Alc. 139-140, E. IT. 236-237, E. Or. 850-851 y 1366-1368, y E. Hipp. 1151-1152.

36 Deyanira en S. Tr. 225-228, Dioniso en E. Ba. 656-660, Medea en E. Med. 1116-1120 y Creonte en E. Ph. 1332-1334.

37 Cf. S. Ant. 385, S. El. 660-661, E. Hec. 485-486, E. IA. 1532-1533, E. Io. 1106-1108, E. IT. 1284-1287, y E. Ph. 1069-1071.

38 Cf. (1) y A. Supp. 600-601, A. Th. 40-41, S. Ai. 201-207, S. Ant. 223-236 y 1155-1171, S. OT. 1222-1231, S. OC. 1579-1582, E. Ba. 1024-1028, E. El. 761-764, E. Hel. 597-600 y 1512-1513, E. Heracl. 784-787, E. HF. 910, E. Rh. 260-261 y 729, E. Supp. 634-640, E. Andr. 1070-1072, y E. Cyc. 375-377.

39 Cf. A. Supp. 600-604, A. A. 538-550 y 615-635, S. Aj. 206-283, S. Tr. 871-898, S. OT. $1222-$ 1236, S. OC. 1579-1585, E. Alc. 141-151, E. Ba. 1024-1043, E. HF. 910-921, E. Io. 1106-1120, E. Rh. 729-755, E. Supp. 634-649, E. Andr. 1070-1084 y E. Cyc. 375-381.

40 Véase S. R. PERris, art. cit., p. 4 y idem, "Perspectives on Violence in Euripides'

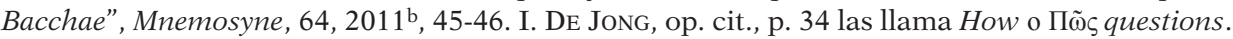
Nosotros las denominamos I-questions, pues esta es la letra por la que comienza la mayoría. Con $\pi \tilde{\omega} \varsigma$, cf. A. A. 543, S. Ant. 406, S. OC. 1585, E. Hel. 1523, E. Io. 1118, E. Med. 1134, E. Rh.

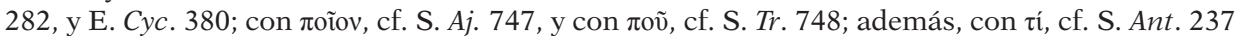

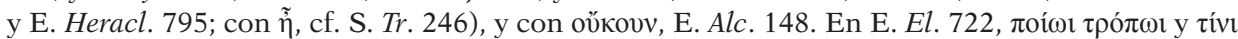

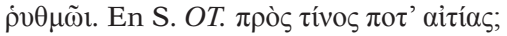

41 Eï $\pi \alpha \tau \varepsilon$ en S. Ant. 1190; $\lambda \varepsilon^{\prime} \gamma^{\prime}$ en E. Ba. 672, E. Or. 1393 y E. IT. 1325; $\varphi \rho \alpha ́ \zeta^{\prime}$ en E. IA. 1539

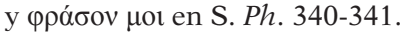

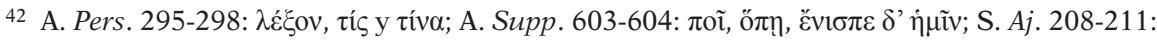

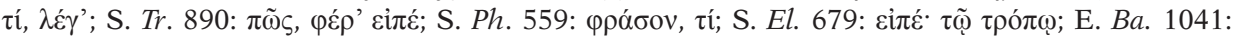

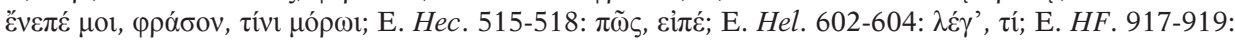

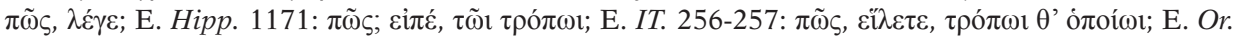

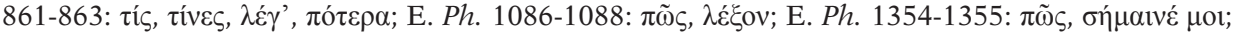

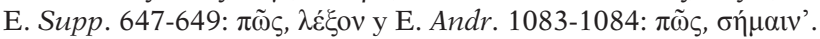


La única excepción está en la intervención del auriga en Reso, pues el corifeo no se dirige a él con una П-question ni con un imperativo, pero extrae la siguiente conclusión antes de que pronuncie su relato:

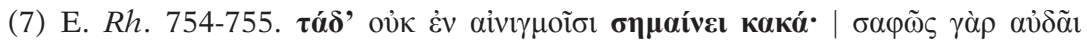

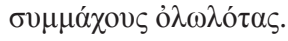

No nos indica con enigmas estas desgracias, pues claramente nos refiere que los aliados están muertos.

El prólogo esticomítico es una convención que se repite para dar paso al relato de mensajero ${ }^{43}$ y es en esta parte donde encontramos con mayor

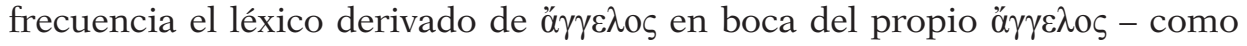
hemos comprobado en el ejemplo (6), en el que el mensajero deja claro que va a anunciar ( $\dot{\alpha} \gamma \gamma \varepsilon \dot{\varepsilon} \lambda \lambda \varepsilon v v)$ noticias desgraciadas, o con otra de las fórmulas

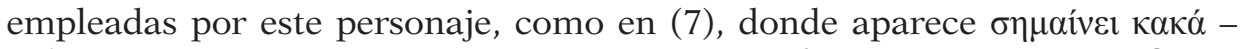
o de otros personajes que anticipan que van a recibir nuevas o que se refieren a ellas cuando el ă $\gamma \gamma \varepsilon \lambda$ o $\varsigma$ ya se las ha comunicado.

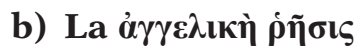

Esta expresión fue acuñada, en su Praeparatio sophistica ${ }^{44}$, por el gra-

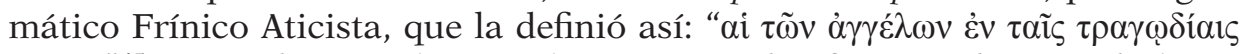

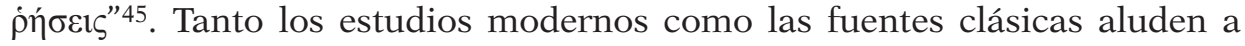
una notable longitud de estas $\dot{\rho} \tilde{\sigma} \sigma \iota_{1} \varsigma^{46}$ y es cierto que muchas rondan los cien versos y algunas superan el centenar, pero también lo es que las hay muy breves.

Más allá de su extensión, resulta interesante, bajo nuestro punto de vista, la aportación de Perris ${ }^{47}$, que pone el énfasis en el aspecto puramente informativo de lo que denomina report-narrative y que se articula en torno a un relato narrativo ${ }^{48}$, unas noticias acaecidas fuera de la escena que un emisor ha de transmitir a su interlocutor y la condición de testigo directo del informante, que también nosotros establecemos como criterio.

43 Cf. M. Halleran, "Episodes", in J. Gregory (ed.), A Companion to Greek Tragedy, Malden, Blackwell, 2005, p. 14; o S. P. Mills, "The Death of Ajax", The Classical Journal, 76, $1981,129-135$.

44 J. De Borries, Phrynichi Sophistae Praeparatio Sophistica, Leipzig, Teubner, 1911, p. 45.

45 Mannsperger, "Die Rhesis", in W. Jens (ed.), Die Bauformen der griechischen Tragödie, München, Wilhelm Fink, 1971, pp. 143-181 propone un intento de clasificación partiendo de la $\dot{\eta} \sigma ı \varsigma$ de mensajero.

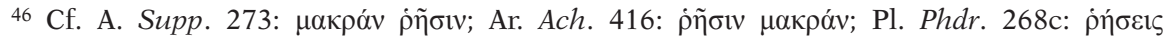

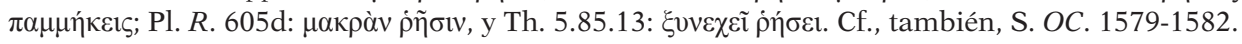

47 Cf. S. R. PERris, loc. cit., $2011^{\mathrm{a}}$, p. 4.

48 Rasgo que comparten todas las j́́бєıৎ excepto las de Siete contra Tebas, que son descriptivas. M. BRIOSo SÁNCHEZ, "Sobre las convenciones escénicas de la tragedia y la comedia clásicas”, in M. Brioso Sánchez, A. Villarrubia Medina (edd.), Aspectos del teatro griego antiguo, Sevilla, Universidad de Sevilla, 2013b, p. 210, relaciona el carácter narrativo con el informativo y concluye que es herencia de la épica. 


\section{c) El epílogo}

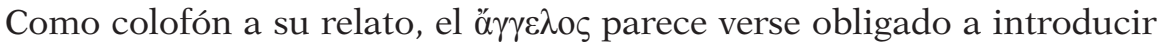
un añadido de tipo gnómico, que suele ser una sentencia, un consejo o una invitación a la reflexión dirigida al receptor de las nuevas. A continuación, lo más habitual es que el mensajero se marche, aunque hay excepciones en las que permanece en escena y es interrogado por su interlocutor, que desea ampliar la información ${ }^{49}$.

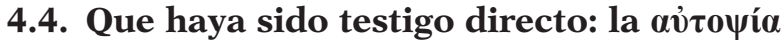

La ả̉iowía - la acción de ver algo con los propios ojos - como prueba de que la información es fidedigna juega un papel fundamental en la transmisión de noticias y es explotada al máximo por los mensajeros trágicos, por lo que debe ser otro criterio a tener en cuenta para su catalogación. Casi todos los ö $\gamma \gamma \varepsilon \lambda$ or evidencian su condición de espectadores y De Jong ${ }^{50}$ afirma que actúan así porque son conscientes de que sus palabras son la única fuente de información fiable de la que disponen los personajes que reciben las noticias

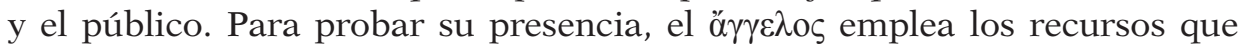
exponemos a continuación.

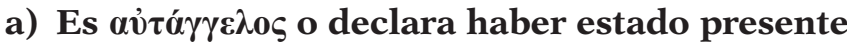

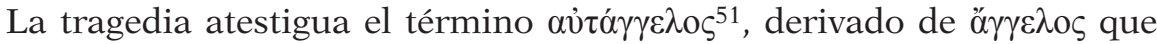
alude al hecho de transmitir una noticia en persona. En (8) Ismene comparece ante su padre, Edipo, que le pregunta si el motivo de su regreso es la nostalgia. Ella responde:

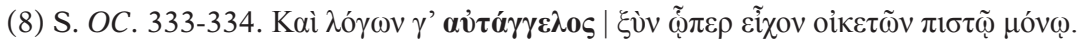

Sí, y como mensajera de noticias que he visto ${ }^{52}$ junto con este sirviente, el único fiel.

A continuación, Edipo se interesa por Eteocles y Polinices e Ismene le anuncia la funesta nueva: se han dado muerte el uno al otro.

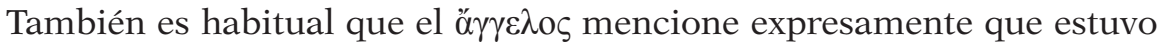
donde se produjo la noticia, como en (9). El mensajero ya ha informado de la derrota persa:

49 En Esquilo no hay excepciones. Sófocles mantiene en escena a Tecmesa, al mensajero en Ayante, al guardián y al mensajero en Antígona, a Neoptólemo en Filoctetes y al pedagogo en Electra. Por su parte, en las tragedias de Eurípides solo se quedan el frigio de Orestes, el pastor

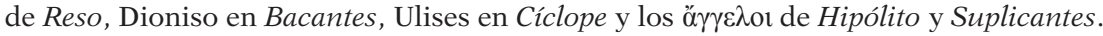

50 I. DE JONG, op. cit., pp. 9-11.

51 Se testimonia en el ejemplo (8) y en S. Ph. 568, donde se atribuye a Odiseo.

52 Cf. LSJ: "Bringing news of what oneself has seen", s.u. 


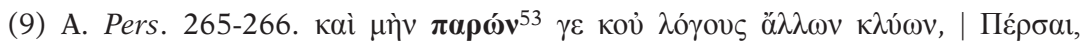

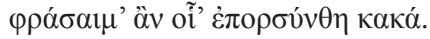

Como yo estaba presente y, ciertamente, no he oído palabras de otros, persas, puedo contaros las desgracias que allí se produjeron.

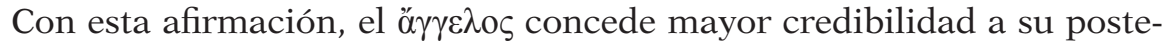
rior relato y tanto los espectadores como los receptores de las noticias ${ }^{54}$ la asumen con facilidad.

\section{b) Realiza su relato en primera persona}

Como testigo visual, el mensajero suele referir los hechos en primera persona. Pensemos, por ejemplo, en el relato de mensajero de Hipólito

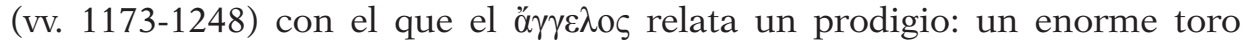
surgió de una ola gigante y arremetió contra el propio Hipólito, que acabará muriendo al final de la tragedia.

Su presencia en el lugar de los hechos queda de manifiesto desde la primera palabra del relato: $\dot{\eta} \mu \varepsilon \tilde{c}$. En este caso, se trata de un plural con el que se refiere tanto a él como al resto de acompañantes de Hipólito y que

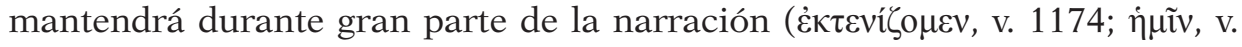

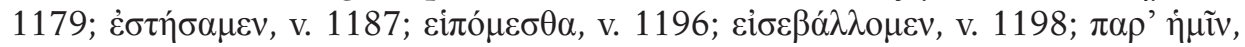

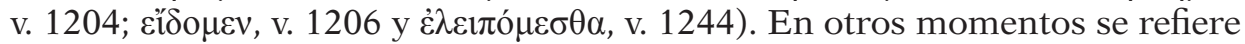

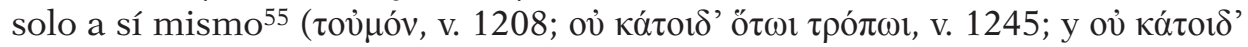

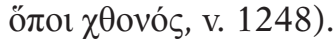

\section{c) Es $\dot{\varepsilon} \xi \tilde{\alpha} \gamma \gamma \varepsilon \lambda 0 \varsigma$ y sale para anunciar lo que ha presenciado}

Siempre que interviene un $\dot{\varepsilon} \xi \alpha ́ \alpha \gamma \varepsilon \lambda$ os la veracidad de sus noticias se da por supuesta, pues sale de un interior para relatar lo que ha presenciado. Aun así, el propio $\dot{\varepsilon} \xi \alpha ́ \alpha \gamma \varepsilon \lambda o \varsigma$ deja claro que ha estado dentro o lo aclara si alguien le pregunta. Esto ocurre, por citar solo un caso, con el esclavo frigio ${ }^{56}$ que relata, en Orestes, el terrible espectáculo que acaba de producirse en palacio: Orestes y Pílades han intentado matar a Helena.

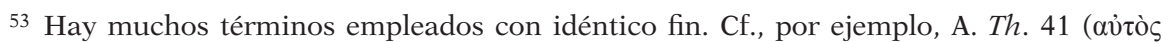

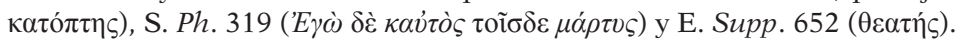

54 En ocasiones, el destinatario lo da por hecho (cf. E. Supp. 647-649). También es frecuente que el mensajero no sea un simple espectador, sino que participe en los acontecimientos (cf. E. Ph. 1072-1074).

55 Sobre la presencia del “nosotros” frente al “yo”, cf. DE JoNG, op. cit., pp. 3-5.

56 Véase M. C. Encinas Reguero, "La estructura del Orestes de Eurípides y el enigmático relato del frigio”, Cuadernos de Filología Clásica: Estudios griegos e indoeuropeos, 21, 2010, 119-133. Sobre esta figura, cf. también M. F. SILVA, "Osadías dramáticas en Eurípides”. El frigio en el Orestes”, in F. De Martino, C. Morenilla (edd.), A la sombra de los héroes, Bari, Levante Editori, 2014, pp. 269-283. 


\section{d) Ha visto o ha escuchado: emplea verbos de percepción}

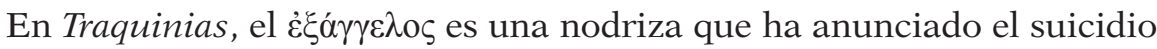
de Deyanira:

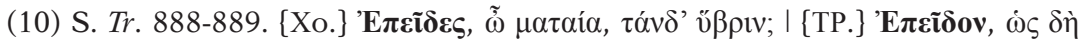
$\pi \lambda \eta \sigma i ́ \alpha \pi \alpha \rho \alpha \sigma \tau \alpha \dot{\tau} \iota \varsigma$.

Corifeo. - ¿Has visto tú, insensata, tal desmesura? Nodriza. - La he visto, porque, precisamente, estaba a su lado.

Tanto el corifeo como la nodriza emplean un verbo de percepción que remite a la visión ${ }^{57}$ de la escena y que ratifica la condición de testigo directo de la portadora de noticias ${ }^{58}$. Este recurso es una constante en las escenas

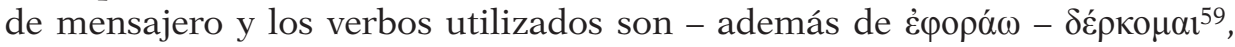

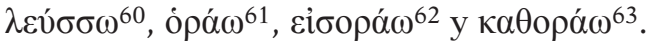

En otras ocasiones - casi siempre cuando la noticia es un milagro - el mensajero no menciona lo que ha visto, sino lo que ha oído y, para hacerlo,

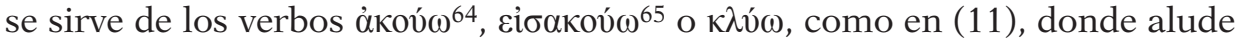
tanto al oído como a la vista:

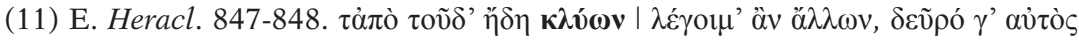

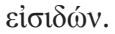

Lo de después puedo contártelo tras haberlo oído de otros; hasta aquí, por haberlo observado yo mismo.

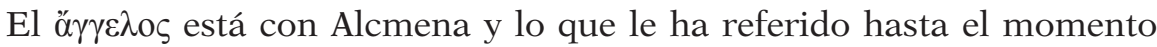
es la victoria de su ejército; lo que mencionará a continuación, un prodigio: el rejuvenecimiento de Yolao.

\section{e) Incluye, en estilo directo, testimonios de los protagonistas}

Se trata de una técnica sobre la que han llamado la atención quienes se han aproximado al estudio de los relatos de mensajero y que se atribuye a la

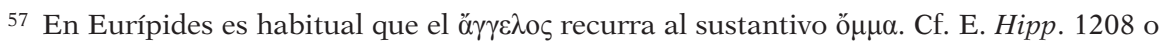
E. Andr. 1087.

58 Sobre esta nodriza, cf. N. Llagüerri Pubill, Nodrizas de tragedia. Mujeres al servicio del teatro griego, Valencia, JPM Ediciones, 2015, pp. 151-178, que enfatiza la relevancia del verbo que emplea, pues hace referencia a cómo ha conocido la muerte de Deyanira: siendo testigo directo del suceso.

59 Cf., también, S. Tr. 747.

60 Cf. E. Supp. 684, E. Ba. 622 y E. Rh. 773.

61 Cf., por ejemplo, S. Tr. 912, S. Ant. 404 y 432 o E. IT. 323.

62 Cf., por ejemplo, E. Hipp. 1208 o E. Heracl. 848.

63 Cf. S. Ant. 1221

${ }^{64}$ Cf. E. IT. 320 y E. Rh. 300.

65 Cf. S. OC. 1645. 
influencia de la épica ${ }^{66}$. En (12), por ejemplo, el mensajero de Hipólito refiere así el lamento de su amo:

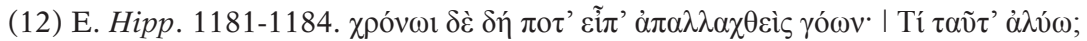

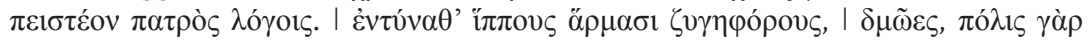

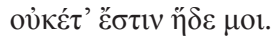

Y poco después, cesando en sus lloros, dijo: “¿Por qué sufro esta angustia? Debo obedecer las palabras de mi padre. Enganchad a mi carro los caballos portadores de yugo, servidores, pues esta ciudad ya no me pertenece".

La $\alpha$ $\tau o \psi i ́ \alpha$, como vemos, es una cualidad propia del ő $\gamma \gamma \varepsilon \lambda o \varsigma$ trágico y su principal consecuencia es que nadie pone en duda la veracidad de las noticias que este personaje comunica ${ }^{67}$. A la confianza de la que son dignos los ă $\gamma \varepsilon \lambda$ or contribuye el hecho de que, como ya hemos señalado, la mayoría sean sirvientes y estén caracterizados por su lealtad. Tanto es así, que incluso en aquellos casos en los que un personaje quiere comunicar noticias falsas lo hace adoptando las mismas convenciones de los ö $\gamma \gamma \varepsilon \lambda$ or que hemos indicado a lo largo de este trabajo.

Situémonos en la Electra de Sófocles. Orestes quiere vengar la muerte de su padre y, en el prólogo, le pide a un pedagogo que entre en palacio con el cometido de llevar una noticia que no se ha producido: "Anuncia (ő $\gamma \gamma \varepsilon \lambda \lambda \varepsilon$ ) que Orestes está muerto a causa de un fatal accidente en los juegos Píticos tras caerse del carro" (S. El. 47-49). El imperativo ő $\gamma \gamma \varepsilon \lambda \lambda \varepsilon$ no puede ser más significativo, pues Orestes ordena al anciano que se comporte como un

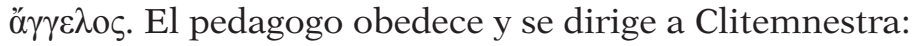

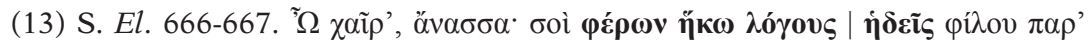

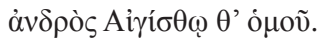

¡Salud, reina! Vengo con dulces noticias de parte de un hombre amigo para ti y, a la vez, para Egisto.

El sirviente hace referencia a las noticias con una de las fórmulas de

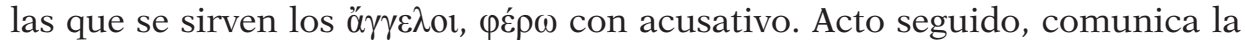
falsa nueva y la desarrolla con un espléndido relato de ochenta y tres versos (S. El. 680-763) ${ }^{68}$ propio del mejor de los mensajeros a pesar de ser inven-

${ }^{66}$ DE Jong, op. cit., pp. 131-139 señala que en Eurípides la inclusión de estilo directo responde a cinco motivos: 1) El mensajero se ve afectado; 2) Incluye exhortaciones; 3) Cita discursos con información esencial para entender la acción; 4) Incrementa el pathos dramático y 5) Los testimonios enfatizan la noticia.

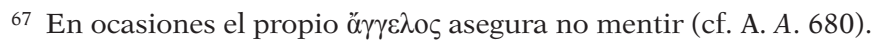

68 C. W. Marshall, "How to write a Messenger-Speech (Sophocles-Elektra 680-763)", Bulletin of the Institute of Classical Studies, 87, 2006, 203-221, afirma que es el único deception speech en el que para mentir se adopta conscientemente el relato de mensajero. No estamos de acuerdo, pues también lo hacen Orestes en Coéforos, Licas en Traquinias y Neoptólemo y un mercader en Filoctetes. Todos ellos son portadores de noticias falsas y también recurren a

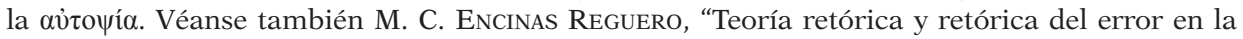
Electra de Sófocles”, Argos, 32, 2009, 65-84 o D. RaEburn, Greek Tragedies as Plays for Performance, Oxford, Wiley Blackwell, 2017, pp. 123-136. 
tado que finaliza con un remate perfecto: la $\alpha$ $\tau o \psi i ́ \alpha$ característica de un fidedigno ớ $\gamma \varepsilon \lambda$ os:

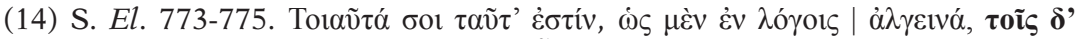

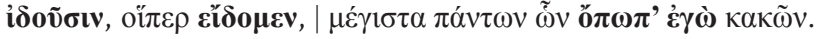

Tales son los hechos, según el relato, dolorosos, pero para quienes los vieron, como nosotros los vimos, la más grande de las desgracias que yo he contemplado.

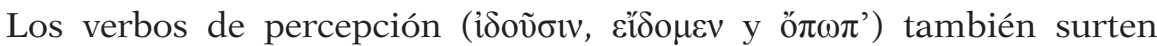
efecto: la mentira no ha sido descubierta, su credibilidad está intacta, como le indica Clitemnestra:

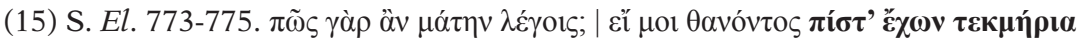
| $\pi \rho \circ \sigma \tilde{\eta} \lambda \theta \varepsilon \varsigma$.

¿Cómo puedes decir que en vano si con fidedignas pruebas del que ha muerto has llegado?

\section{Resultados del estudio}

Teniendo en cuenta los criterios que hemos establecido, presentamos a continuación tres tablas con nuestra propuesta de personajes que han de clasificarse como ä $\gamma \gamma \varepsilon \lambda$ ot. Por razones obvias de espacio y, considerando

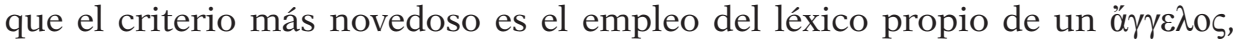
señalamos todas las referencias al mismo (entre paréntesis, el verso o versos concretos $)^{69}$. En dicho apartado especificamos tanto el vocabulario de la familia léxica derivada de ö $\gamma \gamma \varepsilon \lambda o \varsigma$ que usa el mensajero u otro personaje que alude a él y a sus noticias en algún momento de la obra ${ }^{70}$ como el resto de

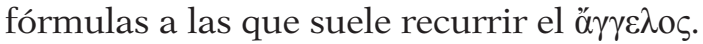

Incluimos en nuestro catálogo a las siguientes personas que no son anónimas y sobre las que no hay consenso: en Esquilo, a Dánao en Suplicantes y a Orestes en Coéforos; en Sófocles, a Tecmesa en Ayante, Hilo en Traquinias, Neoptólemo en Filoctetes e Ismene en Edipo en Colono y, en Eurípides, a Dioniso en Bacantes, a Ulises en Cíclope y a Taltibio en Hécuba.

El caso de Taltibio merece mención aparte, pues es el heraldo de Agamenón, un $\kappa \tilde{\eta} \rho v \xi$, figura con características propias. En principio, la diferencia entre el $\ddot{\alpha} \gamma \gamma \varepsilon \lambda \circ$ y $_{\text {y }}$ el $\kappa \tilde{\eta} \rho v \xi$ es sencilla pues, siguiendo a Longo ${ }^{71}$, el ö $\gamma \gamma \varepsilon \lambda$ o transmitiría noticias, mientras que el $\kappa \tilde{\rho} \rho v \xi$ se ocuparía, entre otras

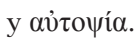

69 Todos cumplen los otros criterios: función informativa, escena con estructura tripartita

${ }^{70}$ Lo que explica que, en las tablas, algunas referencias se produzcan antes o después de los que señalamos como versos de la escena, pues con estos nos referimos en exclusiva a la escena de mensajero.

71 O. Longo, loc. cit., 72. 
cosas, de comunicar mensajes y órdenes y de pregonar proclamas oficiales ${ }^{72}$. Sin embargo, la distinción no es siempre tan evidente, como indica, por ejemplo, el hecho de que Homero califique como ö $\gamma \gamma \varepsilon \lambda o r$ a los heraldos Taltibio, Euribates y Tideo ${ }^{73}$. En la tragedia hay que destacar algunos casos y Taltibio es uno de ellos. Los estudiosos coinciden en que debe clasificarse

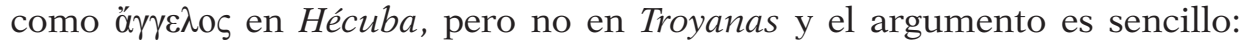
en Hécuba anuncia una noticia (la muerte de Políxena) y protagoniza una

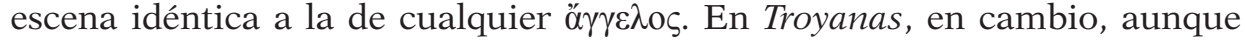
comunica una nueva (las esclavas han sido sorteadas) y emplea el léxico de

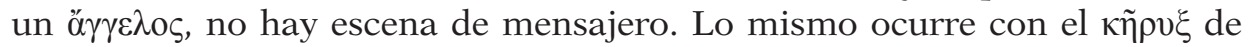
Agamenón tras el que, como indica Pallí Bonet ${ }^{74}$, subyace Taltibio. Nuestro

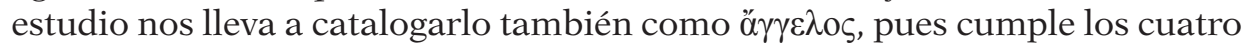
criterios que proponemos.

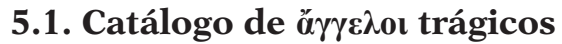

\begin{tabular}{|c|c|c|c|}
\hline \multicolumn{4}{|c|}{ 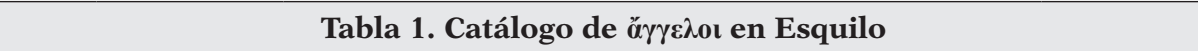 } \\
\hline Obra & Personaje & Léxico & $\begin{array}{l}\text { Versos de } \\
\text { la escena }\end{array}$ \\
\hline Pers. & 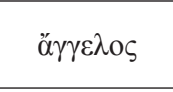 & 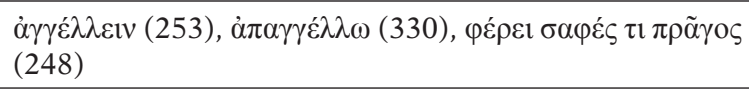 & $249-514$ \\
\hline$T h$. & 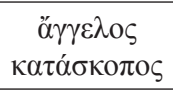 & 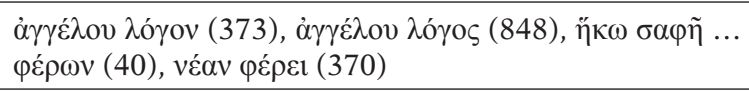 & $375-652$ \\
\hline Supp. & Dánao & 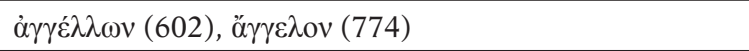 & $600-624$ \\
\hline A. & $\kappa \tilde{\rho} \rho \xi$ & 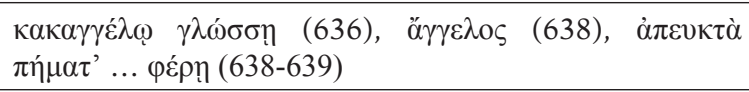 & $503-680$ \\
\hline Ch. & Orestes & 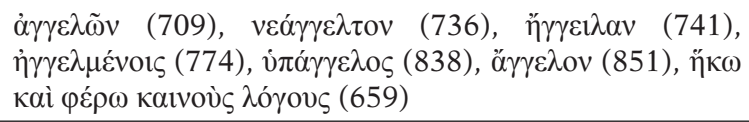 & $653-690$ \\
\hline
\end{tabular}

\begin{tabular}{|c|c|c|c|}
\hline \multicolumn{4}{|c|}{ 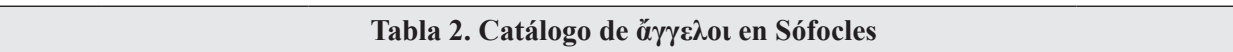 } \\
\hline Obra & Personaje & Léxico & $\begin{array}{l}\text { Versos de } \\
\text { la escena }\end{array}$ \\
\hline \multirow{2}{*}{$A j$. } & Tecmesa & $\grave{\alpha} \gamma \gamma \varepsilon \lambda i ́ \alpha v(222)$ & $201-330$ \\
\hline & 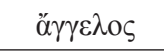 & 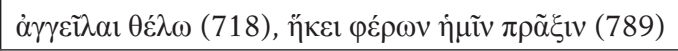 & $718-802$ \\
\hline \multirow{3}{*}{ Tr. } & Licas & 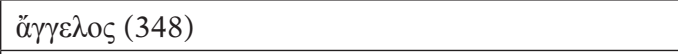 & $229-334$ \\
\hline & Hilo & $\dot{\alpha} \gamma \gamma \varepsilon \dot{\lambda} \lambda \lambda \varepsilon \tau \alpha 1$ (73) & $734-820$ \\
\hline & 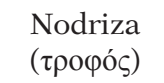 & 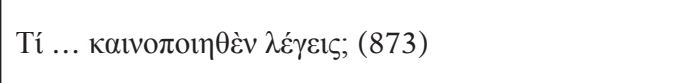 & $871-946$ \\
\hline
\end{tabular}

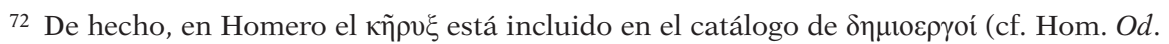

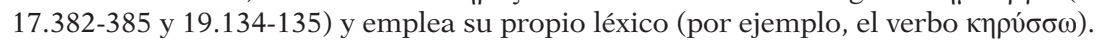

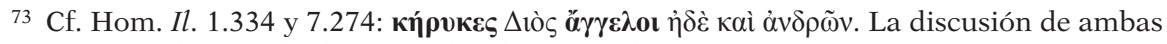
figuras está recogida en todos los capítulos de corpus de R. ForNIELES SÁnCHEZ, op. cit.

74 J. Pallí Bonet, “Los heraldos, Taltibio y Eurípides”, Helmántica, 7, 1956, 345-355. 


\begin{tabular}{|c|c|c|c|}
\hline \multicolumn{4}{|c|}{ 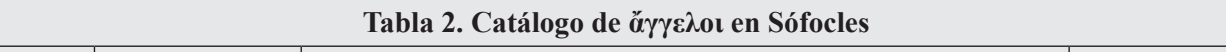 } \\
\hline Obra & Personaje & Léxico & $\begin{array}{l}\text { Versos de } \\
\text { la escena }\end{array}$ \\
\hline \multirow[t]{2}{*}{ Ant. } & $\begin{array}{l}\text { Guardián } \\
(\varphi v ́ \lambda \alpha \xi)\end{array}$ & 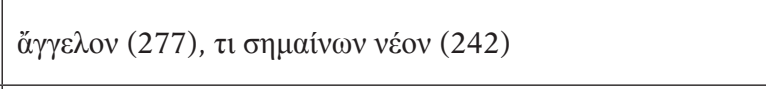 & $\begin{array}{c}223-330 \text { y } \\
384-441 \\
\end{array}$ \\
\hline & $\ddot{\alpha} \gamma \gamma \varepsilon \lambda \mathrm{o \varsigma}$ & 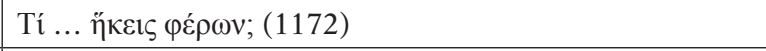 & $1155-1256$ \\
\hline$O T$ & $\dot{\varepsilon} \xi \alpha ́ \gamma \gamma \varepsilon \lambda \mathrm{\alpha}$ & 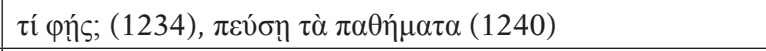 & $1222-1296$ \\
\hline El. & $\begin{array}{c}\text { Pedagogo } \\
\left(\pi \alpha 1 \delta \alpha \gamma \omega \gamma \varsigma_{\varsigma}\right)\end{array}$ & 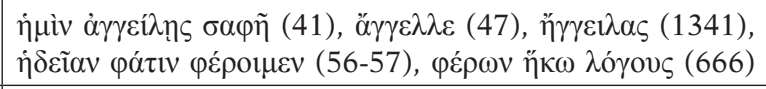 & $660-803$ \\
\hline \multirow[b]{2}{*}{ Ph. } & Neoptólemo & 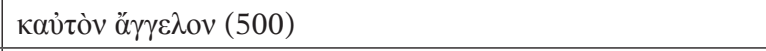 & $319-390$ \\
\hline & $\begin{array}{l}\text { Mercader } \\
(\ddot{\varepsilon} \mu \pi \mathrm{o} о \varsigma)\end{array}$ & 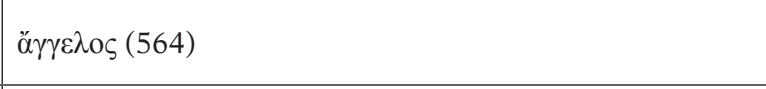 & $542-627$ \\
\hline \multirow{2}{*}{$O C$} & Ismene & 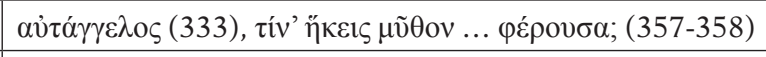 & $325-509$ \\
\hline & ä $\gamma \gamma \varepsilon \lambda \circ \varsigma$ & 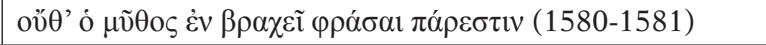 & $1579-1670$ \\
\hline
\end{tabular}

\begin{tabular}{|c|c|c|c|}
\hline \multicolumn{4}{|c|}{ 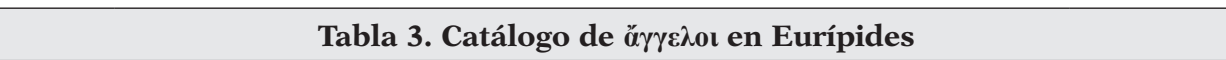 } \\
\hline Obra & Personaje & Léxico & $\begin{array}{l}\text { Versos de } \\
\text { la escena }\end{array}$ \\
\hline Alc. & $\begin{array}{l}\text { Sirvienta } \\
(\theta \varepsilon \rho \alpha ́ \pi \alpha \iota v \alpha)\end{array}$ & 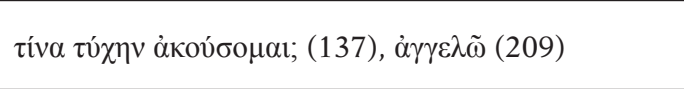 & $141-212$ \\
\hline Med. & 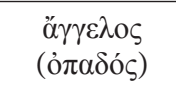 & $\grave{\alpha} \gamma \gamma \varepsilon \lambda \varepsilon \tilde{\imath}(1120)$ & $1121-1230$ \\
\hline Heracl. & ö $\gamma \gamma \varepsilon \lambda \mathrm{os}$ & 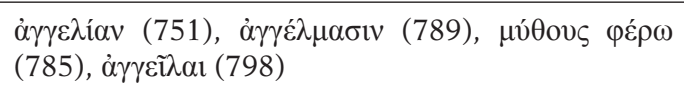 & $784-891$ \\
\hline Hipp. & 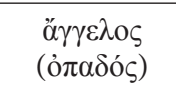 & 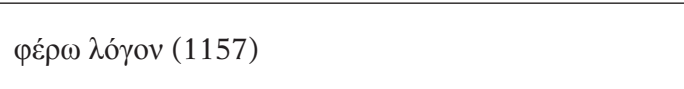 & $1163-1254$ \\
\hline Andr. & $\ddot{\alpha} \gamma \gamma \varepsilon \lambda \mathrm{os}$ & $\dot{\alpha} \gamma \gamma \varepsilon \lambda \tilde{\omega} \nu(1070)$ & $1070-1165$ \\
\hline Hec. & Taltibio & $\dot{\alpha} \gamma \gamma \varepsilon \lambda \theta \varepsilon \tilde{\imath} \sigma \alpha(591)$ & $483-608$ \\
\hline Supp. & 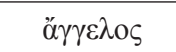 & 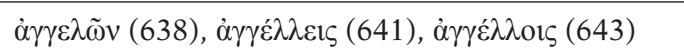 & $634-730$ \\
\hline El. & 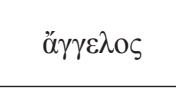 & 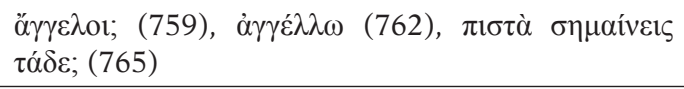 & $761-858$ \\
\hline$H F$ & $\dot{\varepsilon} \xi \alpha ́ \gamma \gamma \varepsilon \lambda \mathrm{\alpha}$ & 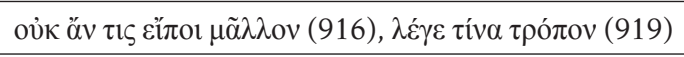 & 909-1015 \\
\hline \multirow[t]{2}{*}{$I T$} & 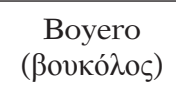 & 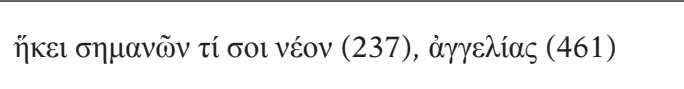 & 238-339 \\
\hline & $\ddot{\alpha} \gamma \gamma \varepsilon \lambda \mathrm{os}$ & $\dot{\alpha} \gamma \gamma \varepsilon \dot{\lambda} \lambda \omega \nu(1306)$ & $1284-1419$ \\
\hline Io. & $\begin{array}{l}\text { Sirviente } \\
(\theta \varepsilon \rho \alpha ́ \pi \omega v)\end{array}$ & 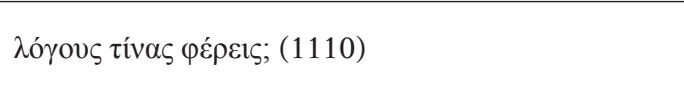 & $1106-1228$ \\
\hline \multirow{2}{*}{ Hel. } & ö $\gamma \gamma \varepsilon \lambda \circ \varsigma 1$ & 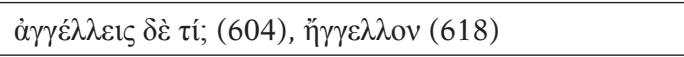 & $597-621$ \\
\hline & $\ddot{\alpha} \gamma \gamma \varepsilon \lambda \circ \varsigma 2$ & $\dot{\alpha} \gamma \gamma \varepsilon \lambda \circ \tilde{v} v \tau \alpha(1617)$ & $1526-1618$ \\
\hline \multirow[b]{2}{*}{$P h$. } & ă $\gamma \gamma \varepsilon \lambda \circ \varsigma 1$ & $\dot{\alpha} \gamma \gamma \varepsilon \lambda \tilde{\omega} \nu(1075)$ & $1067-1263$ \\
\hline & 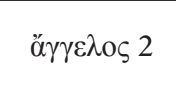 & 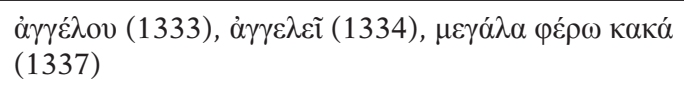 & $1335-1479$ \\
\hline
\end{tabular}




\begin{tabular}{|c|c|c|c|}
\hline \multicolumn{4}{|c|}{ 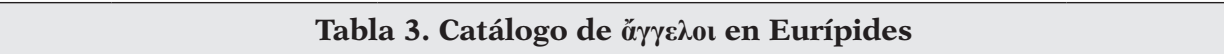 } \\
\hline Obra & Personaje & Léxico & $\begin{array}{l}\text { Versos de } \\
\text { la escena }\end{array}$ \\
\hline \multirow{2}{*}{ Or. } & 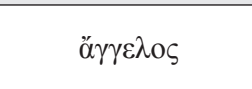 & 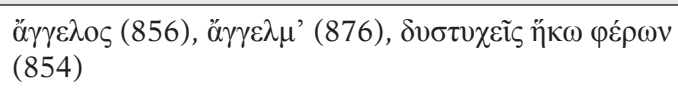 & $852-956$ \\
\hline & $\begin{array}{c}\text { Siervo frigio } \\
\left(\varphi \rho v ́ \xi \pi \rho \sigma^{\prime} \sigma \pi \lambda \circ \varsigma\right)\end{array}$ & $\dot{\alpha} \gamma \gamma \varepsilon \dot{\lambda} \lambda \omega \mu \varepsilon v(1539)$ & $1369-1526$ \\
\hline \multirow{3}{*}{$B a$. } & Dioniso & $\kappa \lambda v_{\varepsilon} \tau^{\prime} \varepsilon \dot{\varepsilon} \mu \tilde{\alpha} \varsigma \kappa \lambda v ́ \varepsilon \tau^{\prime} \alpha v ̉ \delta \tilde{\alpha} \varsigma(576)$ & $576-641$ \\
\hline & 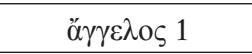 & $\dot{\alpha} \gamma \gamma \varepsilon \lambda \tilde{\omega} \nu(658)$ & $660-774$ \\
\hline & $\ddot{\alpha} \gamma \gamma \varepsilon \lambda \operatorname{lo\varsigma }_{2} 2$ & $\dot{\alpha} \pi \alpha \gamma \gamma \varepsilon \dot{\lambda} \lambda \eta \mathrm{l}(1108)$ & $1024-1052$ \\
\hline$I A$ & 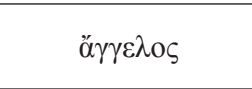 & 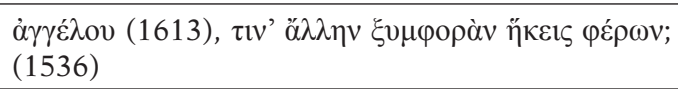 & $1531-1612$ \\
\hline Cyc. & Ulises & 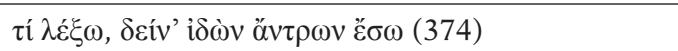 & $374-437$ \\
\hline \multirow{2}{*}{$R h$. } & 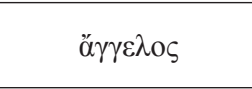 & 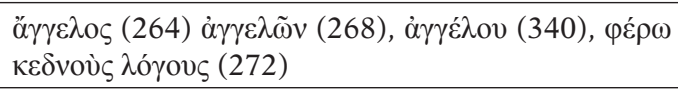 & $264-316$ \\
\hline & 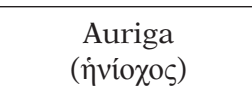 & 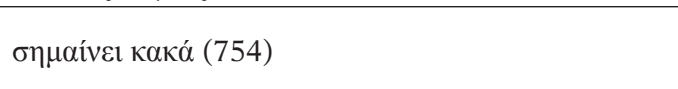 & 729-803 \\
\hline
\end{tabular}

\subsection{Personajes no catalogados como ä $\gamma \gamma \varepsilon \lambda 0 \imath$}

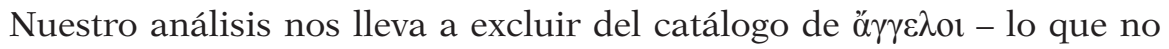
significa que en algunos casos no deba ser tenida en cuenta su relevancia como transmisores de noticias - a los personajes que mostramos en las siguientes tablas. En todas sus intervenciones, excepto en la del primer

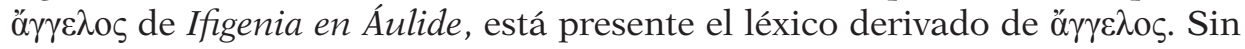
embargo, incumplen uno o varios de los criterios que proponemos.

Algunos son heraldos, como el $\kappa \tilde{\eta} \rho v \xi$ de Suplicantes de Esquilo o Taltibio en Troyanas y ya nos hemos referido a sus funciones. En cambio, otros aparecen como ớ $\gamma \gamma \varepsilon \lambda \mathrm{ol}$ en los manuscritos $\mathrm{y}$, sin embargo, desempeñan papeles más propios de un heraldo.

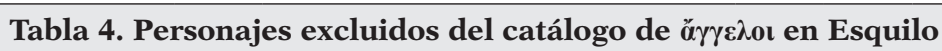

\begin{tabular}{|c|c|c|c|c|c|c|}
\hline \multirow[b]{2}{*}{ Obra } & \multirow[b]{2}{*}{ Personaje } & \multicolumn{5}{|c|}{ Criterio } \\
\hline & & 1 & 2 & 3 & 4 & Versos \\
\hline Supp. & $\kappa \tilde{\eta} \rho v \xi$ & No & Sí: $\alpha \dot{\pi} \alpha \gamma \gamma \varepsilon ́ \lambda \lambda \varepsilon ı v$ (931) & No & No & $836-951$ \\
\hline$P r$. & Hermes & No & Sí: $\alpha \gamma \gamma \varepsilon \lambda \tilde{\omega} \nu$ (942), $\alpha \gamma \gamma \varepsilon \lambda i \alpha \varsigma$ (1040) & No & No & $944-1070$ \\
\hline
\end{tabular}

\begin{tabular}{|c|c|c|c|c|c|c|}
\hline \multirow[b]{3}{*}{ Obra } & \multicolumn{2}{|c|}{ Tabla 5. Personajes excluidos del catálogo de ă $\gamma \gamma \varepsilon \lambda o \iota$ en Sófocles } & & & & \\
\hline & \multirow[b]{2}{*}{ Personaje } & & & & & \\
\hline & & 1 & 2 & 3 & 4 & Versos \\
\hline $\operatorname{Tr}$. & $\ddot{\alpha} \gamma \gamma \varepsilon \lambda \mathrm{os}$ & Sí & Sí: $\alpha \gamma \gamma \varepsilon \dot{\lambda} \omega \nu$ (180), $\alpha \gamma \gamma \varepsilon i ́ \lambda \alpha \varsigma$ (190) & No & No & $180-199$ \\
\hline Ant. & $\dot{\varepsilon} \xi \dot{\alpha} \gamma \gamma \varepsilon \lambda \mathrm{\alpha}$ & Sí & 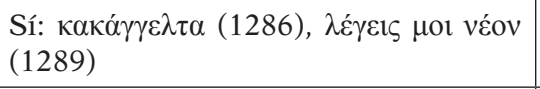 & No & No & $\begin{array}{l}1278- \\
1316\end{array}$ \\
\hline$O T$ & ó $\gamma \gamma \varepsilon \lambda \mathrm{os}$ & Sí & Sí: $\dot{\alpha} \gamma \gamma \varepsilon \lambda \tilde{\omega} \nu$ (955), $\dot{\alpha} \pi \alpha \gamma \gamma \varepsilon \tilde{\lambda} \lambda \alpha 1_{1}$ (958) & No & Sí & $924-1185$ \\
\hline
\end{tabular}




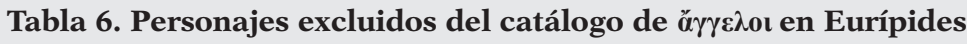

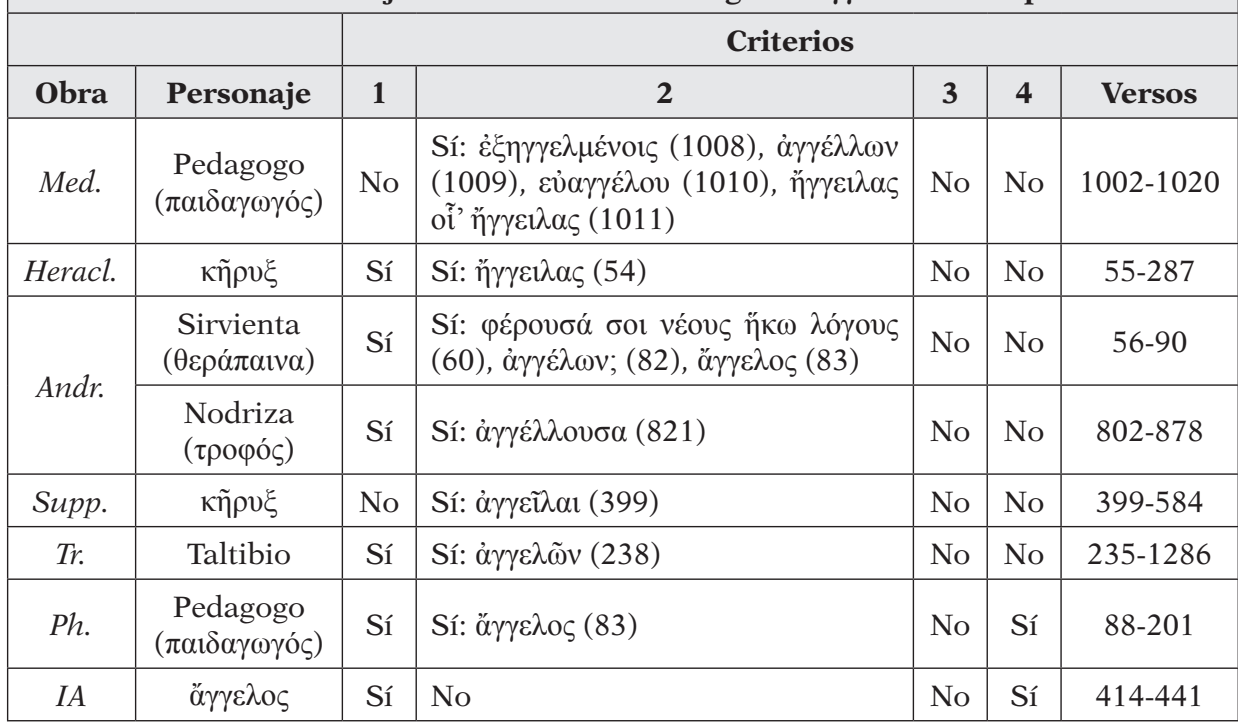

ABSTRACT: Scholars do not agree on the establishment of a general catalogue of messenger scenes in Greek tragedy or on the determination of which characters should be classified as messengers. This paper aims to contribute to advance in their reflections and offers a proposal of classification in which a novel criterion stands out: the consideration of the lexicon that allows us to identify a character as an ơ $\gamma \gamma \varepsilon \lambda \mathrm{os.}$

KEywords: 'A $\gamma \gamma \varepsilon \lambda o \varsigma ;$ Classification; Lexicon. 
COMMENTATIONES

Cartografias de exílio: Ulisses rumo a Ítaca - Ana Paula Pinto ……………………...... 9

Sobre el mensajero trágico: propuesta de clasificación - RAQuel ForNIELES SÁNCHEZ

Daphnis ego in silvis, hinc usque ad sidera notus: una lettura dell'ecl. 5 di Virgilio (e della 10) - PaOla GaGLIARDI.

Fedro un pensador estoico? - ANTONIo CAScón DoRAdo

Las expresiones denigratorias de Marcial sobre su propia obra poética - PEDRo JUAN GALÁN SÁNCHEZ.

Nam et quae vetera nunc sunt, fuerunt olim nova (Quint., Inst. 8.3.34). Arcaicos y clásicos ante los neologismos - SANTIAGo LóPEZ MoredA

Un fragmento del Liber de compunctione cordis de Efrén Sirio (inc. Sicut adstans quis ante regem) - Álvaro CANCELA Cilleruelo

Las fuentes de las Allegoriae quaedam sanctae scripturae (CPL 1190) de Isidoro de Sevilla - Jose Carlos Martín-IgLESIAS

Epistula ad Quiricum Barcinonensem antistitem y Epigramma operis subsequentis de Tajón de Zaragoza. Estudio, edición crítica y traducción - Julia Aguilar Miquel

El manuscrito de Oxford, Bodl. Laud. Lat. 22 (VL 210) y su lugar en la historia textual de la Vetus Latina del libro de los Macabeos - JoAQuín J. SÁnchez GázQuez .......

Antecedentes clásicos en la estética musical de Rodrigo Sánchez de Arévalo: Vergel de los príncipes - INMACULADA RodRíGUEZ-MORENO

Las sentencias atribuidas a Publilio Siro en los florilegios de André Rodrigues de Évora - Francisco Bravo de Laguna Romero.

Ut iuvet et non noceat: médico, paciente y enfermedad en el Introitus de Amato Lusitano a las Curationum medicinalium centuriae - Victoria Recio MuÑoz.....

El copista cretense Antonio Calosinás: problemas de atribución en su primera etapa de actividad (1560-1563) - InMaculada Pérez Martín

Esteban Manuel de Villegas, poeta doctus y filólogo entre Inquisición y Mecenazgo JoRge FERNÁNDEZ LóPEZ / EMILIO dEL Río SANZ

Pervivencia de Ovidio en el poema burlesco Hermafrodito y Sálmacis de Solís y Rivadeneyra y en un romance anónimo - MARía CRUZ GARCÍA FUENTES. 


\section{II}

\section{STVDIA BREVIORA}

O casamento fugaz de Cícero com Publília - Emília M. Rocha de Oliveira

De la critique des poètes à la poétique: la réponse à la critique anti-virgilienne dans les Nuits Attiques d'Aulu Gelle - Benjamin Goldlust.

Una fonte biblica per il carme 88 di Eugenio di Toledo? - Donato De Gianni.....

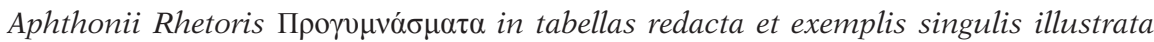
de Matthaeus Bader: Un resumen de los Progymnasmata de Aftonio - MARÍA Dolores García de Paso Carrasco.

El método argumentativo en la Monarchia Mystica de Lorenzo de Zamora - MANUEL ANDRÉs SEOANE RodRíGUEZ

Bartolomé de Alcázar y el De Ratione Dicendi (1681-1688) - MANuel LóPEZ-MuÑoz...

VARIA NOSCENDA

AE 1985, 504 un nuevo carmen epigraphicum en Portugal - JAVIER DEL Hoyo / AlBerto BOLAÑOS-HERRERA.

De nouvelles perspectives pour les textes grecs du LASLA. Avancées dans la banque de données - Camille Denizot / Marc Vandersmissen

\section{IV \\ RES COMMEMORANDAE}

O De Navigatione de Diogo de Sá traduzido e anotado: um acontecimento editorial - José DA SIlva HorTa

\section{LIBRI RECENSITI}

\section{a) Edições de texto. Comentários. Traduções. Estudos Linguísticos}

Carmen Codoñer (ed.), Juan A. González Iglesias (trad.), Priapea - André Filipe SIMÕES

GaLENo, Sobre los pulsos para los principiantes. Sobre la utilidad de los pulsos. Introducción, traducción, notas e índices de Luis Miguel Pino Campos - INMACULADA RODRíGUEZ MORENO

GaLeno, Arte médica. Introducción, traducción, notas e índices de Pascual Espinosa Espinosa - InMaculada RodRíguez MoReno .

GaLeno, Sobre las facultades de los alimentos. Introducción, traducción, notas e índices de María Joana Zaragoza - InMACuladA Rodríguez Moreno 
Galeno, Comentario a Sobre los humores de Hipócrates. Introducción, traducción, notas e índices de José Miguel García Ruiz y Jesús María Álvarez Hoz INMACUlada RodRíGuez MORENO

GaLENo, Sobre la conservación de la salud. Introducción, traducción, notas e índices de Inmaculada Rodríguez Moreno - Luis Miguel Pino Campos 468

\section{b) Literatura. Cultura. História}

M. Oller, J. PÀmias, C. Varias (edd.), Tierra, territorio y población en la Grecia antigua: aspectos institucionales y míticos - NUNo SiMÕES RodRIGUES

Luísa de Nazaré Ferreira, Mobilidade Poética na Grécia Antiga: uma leitura da obra de Simónides - ANA Rita FigueIRA.....

Claire Nancy, Euripide et le parti des femmes - ANA AlEXANDRa Alves de Sousa.

Gary D. Farney, Guy Bradley (edd.), The Peoples of Ancient Italy - Maria João CORREIA SANTOS.

Meghan J. DiLuzio, A Place at the Altar: Priestesses in Republican Rome - Maria CRISTINA PIMENTEL

Robson Tadeu Cesila, Epigrama: Catulo e Marcial - Maria Cristina Pimentel

Martin Stöckinger, Kathrin Winter, ANdreas T. Zanker (edd.), Horace and Seneca: Interactions, Intertexts, Interpretations - RICARDO DUARTE

M. Sanz Morales, R. González Delgado, M. Librán Moreno, J. Ureña Bracero (edd.), La (inter)textualidad en Plutarco. Actas del XII Simposio Internacional de la Sociedad Española de Plutarquistas. Cáceres, 8-10 de Octubre de 2015 JOAQUim PINHEIRO

Michèle Biraud, Michel Briand (edd.), Roman grec et poésie. Dialogue des genres et nouveaux enjeux du poétique. Actes du colloque international, Nice, 21-22 mars 2013 - Fotini HADJITTOFI

Martin T. Dinter, Charles Guérin, Marcos Martinho (edd.), Reading Roman Declamation: Calpurnius Flaccus - Luís Manuel GasPar CERQueira

José Antonio Fernández Delgado, Francisca Pordomingo, La Retórica Escolar Griega y su Influencia Literaria. Edición a cargo de Jesús Ureña y Laura MiguélezCavero - Marília Pulquério Futre Pinheiro.

Sandrine Dubel, Anne-Marie Favreau-Linder, Estelle Oudot (dir.), À l'école d'Homère. La culture des orateurs et des sophistes - RuI Miguel DUARTE

Juan Martos, Rosario Moreno Soldevilla (edd.), La tradición erótica en la poesía latina tardía - PAulo FARMHOUSE AlBerto.

Fortunatianus Aquileiensis, Commentarii in Evangelia = Commentaries on the Gospels. Lukas J. Dorfbauer (ed.) - JosÉ Jacinto FerReIRA DE FARIAS. 
M. Bottazzi, P. Buffo, C. Ciccopiedi, L. Furberta, Th. Granier (orgs.), La società monastica nei secoli VI-XII. Sentieri di Ricerca. Atelier jeunes chercheurs sur le monachisme médiéval, Roma, 12-13 giugno 2014 - Paula Barata Dias....

José Carracedo Fraga, El tratado De uitiis et uirtutibus orationis de Julián de Toledo. Estudio, edición y traducción - PAUlo FARmhouse Alberto

Carolina Cupane, Bettina Krönung (edd.), Fictional Storytelling in the Medieval Eastern Mediterranean and Beyond - Rui CARLos FonsECA......

Widukindo de Corvey, Gestas de los Sajones. Edición, Traducción y notas Pedro Herrera Roldán - Paula Barata Dias

Rino Modonutti, Enrico Zucchi (edd.), "Moribus Antiquis Sibi Me Fecere Poetam". Albertino Mussato nel VII Centenario dell'incoronazione poetica (Padova 13152015) - IsABEL ALMEIDA.

Aires A. Do Nascimento, Voltados à Europa: Livro de Arautos, De ministerio armorum. Admirar e louvar terras e senhores, em 1416, ao tempo do Concílio de Constança - MARc MaYer i Olivé.

Marie-Laure Monfort, Janus Cornarius et la découverte d'Hippocrate à la Renaissance. Textes de Janus Cornarius édités et traduits. Bibliographie des éditions Cornariennes - CRISTINA SANTOS PINHEIRo

Isabel Almeida (org.), Peregrinaçam 1614 - T. F. EARLE

SIlVINA PEREIRA, Dramas Imperfeitos. Teatro clássico português: um repertório a descobrir - MARIA Jỗo BRILHANTE

Nieves Baranda Leturio, Anne J. Cruz, Las escritoras españolas de la Edad Moderna. Historia y guia para la investigación - VANDA ANASTÁcIO.

FrIEDERIKE KRIPPNER, Spielräume der Alten Welt: Die Pluralität des Altertums in Dramentheorie, Theaterpraxis und Dramatik (1790-1870) - ARMANDO SENRA MARTINS .....

JoËL Thomas, Les mythes gréco-romains ou la force de l'imaginaire. Les récits de la construction de soi et du monde-ABEL N. PENA.....

L. FABBri, Il Papavero da Oppio nella Cultura e nella Religione Romana - MARIA FERNANDES

Virginie Leroux, Emilie Séris, Théories Poétiques Néo-Latines, Textes choisis, introduits et traduits sous la direction de... - RICARDo NoBRE

CARMEN GONZÁLEZ-VÁzQuez (ed.), El teatro en otros géneros y otros géneros en el teatro: II estudios de teatro romano en honor del Professor Benjamín García-Hernández. - SOFIA FRADE.

\section{c) Instrumenta}

Tiago C. P. dos Reis Miranda, Mário J. Freire da Silva (coords.), 'Libros relege, volve, lege'. O Livro antigo na Biblioteca do Exército - VANDA ANASTÁcio 